\title{
Sustainability \& Diversity through Chemistry: Together, We Made that Happen
}

For the first time ever in the history of the International Union of Pure and Applied Chemistry (IUPAC), the most important and prestigious Chemistry event in the earth, the World Chemistry Congress (WCC) was hosted in South America. Chemists worldwide and IUPAC members gathered together in São Paulo, Brazil, at the $46^{\text {th }}$ World Chemistry Congress and the $49^{\text {th }}$ General Assembly. ${ }^{1}$ The WCC was organized by the Brazilian Chemical Society (SBQ) together with its traditional Annual Meeting, and it was part of the celebration of the $40^{\text {th }}$ Anniversary of SBQ. The Brazilian Chemical Society, founded in 1977, is the IUPAC National Adhering Organization (NAO) of Brazil and one of the most representative and important scientific associations in Latin America.

The $46^{\text {th }}$ World Chemistry Congress provided a unique opportunity for both IUPAC and SBQ to connect chemists at different stages of their careers, from all over the world, to highlight the importance of chemistry and its major contributions to the welfare of humankind. Also, it was a fruitful forum to share the state-of-the-art and the breakthroughs related to different aspects of the chemical science. In 2017, Brazil was the world capital of Chemistry.

With the theme "Sustainability \& Diversity through Chemistry" the WCC linked all fields of Chemistry, providing a major coverage of the main areas of interest for chemists. Around 700 scientific activities were held, with the participation of more than 3,500 enthusiastic scientists from industry and academia from 66 countries all over the world. Among numerous innovations, we introduced a ground-breaking $360^{\circ}$ stage system that captivated the participants. With up to eight conferences taking place simultaneously in a single space, without separate rooms or dividing walls, the audience managed to watch one or more activities without having to move around.

The scientific program included several plenary lectures, parallel sessions, three special symposia (Research data, big data and chemistry; Women in Chemistry; Young research in chemistry), activities organized by the Chemical Industry, parallel activities organized by the Scientific Divisions of SBQ, one panel discussion regarding the Future of Chemical Science, poster presentations and twelve major symposia centered in the following mean themes: Analytical \& Food Chemistry (AC), Chemistry Education (CE), Chemistry for Industry Innovation (CI), Chemical Synthesis (CS), Energy, Water and Environmental Sciences (EE), Green Chemistry and Biotechnology (GB), Inorganic and Structural Chemistry (IC), Macromolecules and Materials (MM), Medicinal Chemistry and Chemical Biology (MB), Nano Science and Technology (NT), Natural Products and Biodiversity (NB), and Physical, Biophysical and Computational Chemistry (PC). ${ }^{2}$ Approximately 2,400 conference posters were presented by students, researchers, and other professionals within these 12 topics.

During the IUPAC General Assembly in São Paulo, the Council formally ratified the decision of the IUPAC Bureau for the names and symbols of four new elements (for the first time in history), formally named, Nihonium (Nh; $Z=113)$, Moscovium (Mc; $Z=115)$, Tennessine (Ts; $Z=117)$ and Oganesson $(\mathrm{Og}$; $Z=118$ ). The updated Periodic Table, including the four added elements, is available at the IUPAC website. ${ }^{3}$ In our traditional special issue of the SBQ Bulletin, entitled "IUPAC-2017", we have provided important material regarding the congress. ${ }^{4}$ In addition, a beautiful and high quality photo gallery is freely available. $^{5}$

The IUPAC Congress in Brazil surely was a milestone for the Brazilian Chemistry and for all the Brazilian Chemical community, shining light on the high level chemistry produced in this country. Brazil has the $8^{\text {th }}$ biggest Chemical Industry of the world, and publishes around $2 \%$ of all scientific papers in Chemistry, which ranks it among the 15 countries that most publish in this field. IUPAC-2017 was an extraordinarily successful event. Brazil and South America already have their places guaranteed on the world map of Chemistry. IUPAC-2017 is leaving a tangible legacy for the future of the chemical sciences in Brazil and South America, especially in favor of our highly talented young students, who are our future scientists and leaders.

This special issue of the Journal of Brazilian Chemical Society includes some of science presented in the IUPAC WCC. Selected speakers were invited to contribute with reviews, accounts or original papers to be considered for publication. Here we can taste a tiny portion of the scientific richness and the magic atmosphere experienced in São Paulo at July, 2017.

The IUPAC-2017 was an effort of the entire SBQ through many people, who have been hardworking during seven years to make it happen. Our sincere thanks to all who have helped to make this wonderful history a reality!

Adriano D. Andricopulo
Chairman of the IUPAC-2017 Organizing Committee
Universidade de São Paulo (USP), São Paulo-SP, Brazil

Aldo J. G. Zarbin

President of the Brazilian Chemical Society Universidade Federal do Paraná (UFPR), Curitiba-PR, Brazil

\section{References}

1. http://www.iupac2017.org, accessed in March 2018.

2. http://www.iupac2017.org/programme_iupac2017.pdf, accessed in March 2018.

3. https://iupac.org/what-we-do/periodic-table-of-elements, accessed in March 2018

4. https://issuu.com/editoracubo/docs/iupac-2017_en-low, accessed in March 2018.

5. http://www.iupac2017.org/photos.php, accessed in March 2018.

(n)

